\section{Cauces con doble función drenaje-riego en la Huerta del Segura (España): una adaptación planeada del regadío a la aridez y penuria hídrica}

\section{Ditch with double function (drainage-irrigation) in the Huerta del Segura (Spain): a planned irrigation adaptation to the aridity and dearth of water}

\author{
Gregorio Canales Martínez \\ Universidad de Alicante \\ Alicante. España \\ gregorio.canales@ua.es \\ (iD) 0000-0002-7576-9098
}

\section{María Dolores Ponce Sánchez \\ Universidad de Murcia \\ Murcia. España \\ maponce@um.es \\ (iD) 0000-0003-2274-6711}

Información del artículo:

Recibido: 25 mayo 2020

Revisado: 12 diciembre 2020

Aceptado: 28 diciembre 2020

$\begin{array}{ll}\text { ISSN } & 2340-8472 \\ \text { ISSNe } & 2340-7743 \\ \text { DOI } & 10.17561 / \text { AT.18.5542 }\end{array}$

(c) $\mathrm{CC}-\mathrm{BY}$

\section{RESUMEN}

El regadío tradicional establecido en las márgenes del río Segura es el paradigma del dominio del medio por parte de los grupos sociales. La implantación de canales de riego (aguas vivas) y de avenamiento (aguas muertas) posibilitó una transformación revulsivadeesteterritorio paraser colonizado. La reutilización de los caudales de drenaje para regar supuso alcanzar la máxima eficiencia de aprovechamiento en una región semiárida, dar a conocer este hecho y el valor de este patrimonio hidráulico es el doble objetivo de este trabajo. Para ello se aborda un modelo de este ciclo integral del agua con el Azarbe Mayor del Norte, que abastece un sector de las Huertas de Murcia y Orihuela, patrón repetido en otras canalizaciones. El análisis se ha fundamentado en tres fuentes complementarias de información: trabajo de campo, la labor de archivo; finalmente, la revisión de la cartografía digital facilitada por los respectivos órganos gestores.

PALABRAS CLAVE: Huerta, Almarjal, Riego-avenamiento, Colonización, Edificio hidráulico.

\begin{abstract}
The traditional irrigation established on the banks of the Segura River is the paradigm of the dominance of the environment by social groups. The implantation of irrigation canals (living waters) and drainage (dead waters) made possible a revulsive transformation of this territory to be colonized. The reuse of drainage flows for irrigation meant reaching the maximum efficiency of use in a semiarid region, making this fact known and the value of this hydraulic heritage is the double objective of this work. To do this, a model of this integral water cycle is approached with the Azarbe Mayor del Norte, which supplies a sector of the Huertas de Murcia and Orihuela, a pattern repeated in other pipelines. The analysis has been based on three complementary sources of information: field work, archival work; finally, the review of the digital cartography provided by the respective management bodies.
\end{abstract}

KEYWORDS: Orchard, Almarjal, Irrigation-drainage, Colonization, Hydraulic building.

(c) Universidad de Jaén (España).

Seminario Permanente Agua, Territorio y Medio Ambiente (CSIC) 
Canais com dupla função de drenagemirrigação na Huerta del Segura (Espanha): uma adaptação planeada da irrigação à arididade $e$ dificuldades de agua.

\section{RESUMO}

A irrigação tradicional estabelecida nas margens do O Rio Segura é o paradigma do domínio do o meio ambiente por grupos sociais. A implantação de canais de irrigação (águas vivas) e drenagem (águas mortas) tornou possível uma transformação revulsiva deste território a ser colonizado. A reutilização dos fluxos de drenagem parairrigação significava alcançar a máxima eficiência de uso em um semi-árido região, tornando este fato conhecido e o valor desta patrimônio hidráulico é o duplo objetivo deste trabalho. Para fazer isso, um modelo deste ciclo integral da água é abordado com o Azarbe Mayor del Norte, que abastece um setor das Huertas de Murcia e Orihuela, um padrão repetido em outros oleodutos. A análise tem sido baseada em três fontes complementares de informação: trabalho de campo, arquivamento trabalho; finalmente, a revisão da cartografia digital fornecida pelos respectivos órgãos de administração.

PALAVRAS-CHAVE: Pomar, Almarjal, Irrigação-drenagem, Colonização, Edifıcação hidráulica.

Canaux avec double fonction d'arrosagedrainage dans la Huerta del Segura (Espagne): une adaptation planifiée de l'irrigation à l'aridité et aux péneries de l'eau

\section{RÉSUMÉ}

L'irrigation traditionnelle établie sur les rives de la rivière Segura est le paradigme de la domination de l'environnement par les groupes sociaux. L'implantation de canaux d'irrigation (eaux vives) et de drainage (eaux mortes) a permis une transformation révulsive de ce territoire à coloniser. La réutilisation des écoulements de drainage pour l'irrigation signifiait atteindre le maximum d'efficacité d'utilisation en région semi-aride, faire connaître ce fait et la valeur de ce patrimoine hydraulique est le double objectif de ce travail. Pour ce faire, un modèle de ce cycle intégral de l'eau est abordé avec l'Azarbe Mayor del Norte, qui alimente un secteur des Huertas de Murcia et Orihuela, un schéma répété dans d'autres canalisations. L'analyse a été basée sur trois sources d'informations complémentaires: travail de terrain, travail d'archivage; enfin, la revue de la cartographie numérique fournie par les organes de gestion respectifs.

MOTS CLÉs: Verger, Almarjal, Irrigation-drainage, Colonisation, Bâtiment hydraulique.
Canali con doppia funzione di drenaggioirrigazione di Huerta del Segura (Spagna): un adattamento pianificato dell'irrigazione all'aridità e alle difficoltà idriche

\section{SOMMARIO}

L'irrigazione tradizionale stabilita sulle rive del Segura è il paradigma del dominio dell'ambiente dell'ambiente da parte dei gruppi sociali. L'impianto di canali di irrigazione (acque vive) e di drenaggio (acque morte) ha reso possibile una trasformazione revulsiva di questo territorio da colonizzare. Il riutilizzo dei flussi di drenaggio per l'irrigazione significava raggiungere la massima efficienza d'uso in una regione semiarida regione semiarida, far conoscere questo fatto e il valore di questo patrimonio idraulico è il doppio obiettivo di questo lavoro. Per fare questo, un modello di questo ciclo integrale dell'acqua è approcciato con l'Azarbe Mayor del Norte, che alimenta un settore delle Huertas de Murcia e Orihuela, un modello ripetuto in altre condotte. L'analisi si è basata su tre fonti di informazione complementari: lavoro sul campo, lavoro d'archivio; infine, l'esame della cartografia digitale fornita dai rispettivi enti di gestione.

PAROLE CHIAVE: Frutteto, Almarjal, Irrigazione-drenaggio,

Colonizzazione, Edificio idraulico 


\section{El sistema de drenaje, un factor decisivo en la construcción de la Huerta}

Es de destacar, la importancia que los cauces de drenaje alcanzan en la red tradicional de riego implantada en el llano aluvial del río Segura en su tramo final y al inicio del mismo. No solo porque erradica el encharcamiento que se produciría en la planicie, al carecer de pendiente y poseer en el subsuelo un manto de arcillas cuya impermeabilidad no facilita las filtraciones, sino también, porque al realizar la función de regar con esos caudales, procedentes del avenamiento, otorga a este regadío la condición de sostenible. En tanto que se produce un aprovechamiento eficaz de este escaso recurso, el primer acto consuntivo de aguas se reutiliza en varias ocasiones pues pasa a dichos cauces a lo largo de la extensa vega, desde Murcia hasta el Bajo Segura, en tierras que van perdiendo cota hacia la desembocadura (Mapa 1). Por ello, el objetivo de la investigación es poner de manifiesto los valores de este patrimonio hidráulico y especialmente de esta doble función que desempeñan los cauces avenantes. Si bien hay que citar otras aplicaciones que, aunque son realizadas por el resto de infraestructuras, vienen a completar la trascendencia de los mismos. Así, son receptores de pluviales durante los episodios de lluvias torrenciales, coadyuvando las inundaciones, o movieron molinos batanes y harineros.

Todo el conjunto de canalizaciones se encuentra amenazado por intereses urbanísticos, públicos y privados. La intención es exigir a tomadores de decisiones su compromiso con este modelo tradicional de riego, para que permanezca el agropaisaje milenario que ha creado, proveedor de beneficios económicos (espacio de producción, empleo...), sociales (son numerosos los grupos humanos que han sido sujeto y objeto del agrosistema), ambientales (conservan biodiversidad, los cultivos fijan suelo, absorben aguaceros, son sumideros de $\mathrm{CO}_{2}$, expelen oxígeno, contribuyen a favorecer el ciclo del agua...) y culturales (se ha creado un modo de vida pleno de aspectos tangibles e intangibles). Para alcanzar este objetivo se muestra un ejemplo paragdimático, el Azarbe Mayor del Norte, en forma y funcionamiento, que participa en las dos únicas Huertas Históricas de origen andalusí que implementan acueductos para recibir las filtraciones después de los riegos. El análisis ha sido posible por una metodología que combina tres acciones. Observación en el trabajo de campo, se ha recorrido su trazado para localizar los tramos en los que desempeña dichas funciones; labor de archivo, que ha permitido entender la situación y necesidades que condujeron a estas actuaciones; y por último, la revisión de cartografía digital facilitada por los respectivos órganos gestores del regadío para realizar mediciones de esta canalización y representarla espacialmente. La compleja arquitectura del agua que se muestra perdura en esencia desde que la implantara, a partir del siglo VIII ${ }^{1}$, la población egipcia de los yundíes, establecida en la Cora de Tudmir (Orihuela-Murcia) para iniciar, mediante la agrarización de este espacio, uno de los paisajes rurales-culturales más paradigmáticos de las regiones

Mapa 1. Localización del ámbito de estudio

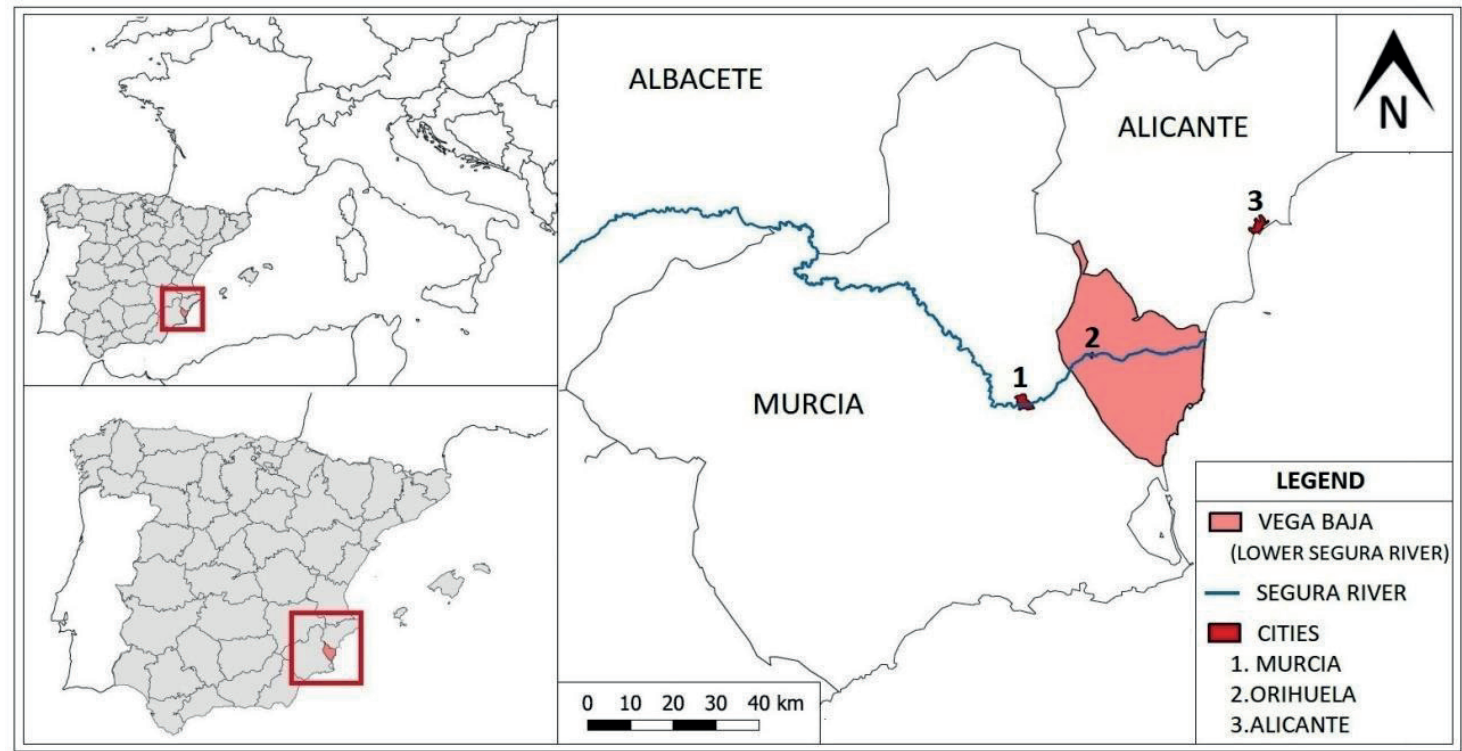

Fuente: Elaboración propia.

1. Gea de, 1995. 
mediterráneas. Una infraestructura que alcanza su madurez y pleno establecimiento durante los siglos XVII y XVIII en las sucesivas ampliaciones que experimenta el espacio regado, generadas tras sanear y colonizar el gran almarjal presente en este territorio hasta la desembocadura del curso fluvial. El objeto de estudio es el patrón del Azarbe Mayor del Norte, un gran colector avenante con nacimiento al noreste de la ciudad de Murcia y que continúa por el término municipal de Orihuela, provincia de Alicante (Mapa 2). La exposición de los rasgos propios que definen un subsistema de tal naturaleza dentro del complejo conjunto hidráulico, así como, las funciones que desempeña en el espacio, verifican la trascendencia del mismo y el interés por estudiarlo.

El determinismo físico que impone el lugar elegido para el asentamiento humano es el factor que confiere relevancia a este prototipo de ingeniería, que prioriza sobremanera el drenaje, aunque a priori, al pensar en la expansión del regadío la función primaria se atribuya a la acción de regar. Este hecho evidencia la perseverancia de la sociedad por ganar para el cultivo las zonas húmedas en un proceso secular que creó la Huerta, fruto de las relaciones de los grupos sociales con su medio. Se trata de unas pautas de adaptación fundamentadas en el ensayo-error que propiciaron la forma idónea de ocuparlo y usarlo hasta nuestros días. En el caso del ejemplo seleccionado supuso la desecación de más de dos mil ha que conformaban el marjal de La Urdienca. Un amplio sector incorporado a la Huerta tras un largo proceso de colonización del territorio y que, por las características de este, antes de su puesta en cultivo presentaba varios ecosistemas diferenciados, constituidos por el citado almarjal junto a carrizales y saladares.

El enclave presentaba gran homogeneidad visual, donde los aludidos hábitats alcanzaban un alto grado de interrelación, al poseer unos carácter pantanoso por ubicarse en las cotas más bajas del interior de la planicie; otros desarrollados en terrenos húmedos con un nivel freático muy alto casi próximo a la superficie, por lo que en ellos prosperaba la vegetación de carrizos que le daba nombre; por último, las tierras secas salinas en las que las altas temperaturas originaban la presencia de una costra blanquecina de cloruro sódico. Estos tres dominios fluctuaban a lo largo del año en virtud de las precipitaciones, de los aportes hídricos por los desbordamientos del río y la confluencia de ramblas, así como, por el afloramiento de varios manantiales que contribuían a mantener el espacio encharcado ${ }^{2}$.

\footnotetext{
2. Canales y De Juanes, 2014.
}

Las referencias documentales del siglo XV verifican la abundante frecuencia de estos ámbitos en La Urdienca, siendo su aprovechamiento de uso común: no se utilizaban "por ser eriazos e carrizales e estar el mas tiempo del año lleno de agua", indicándose en otras ocasiones que las tierras estaban "hechas almarjal" o componían "saladares" o "junquerales"; todos ellos sujetos a un aprovechamiento antrópico de carácter natural que evolucionó al convertirse en Huerta. Las Ordenanzas de Riego del Azud de Alfeitamí de Almoradí, aprobadas en la última década del siglo XVIII, una de las poblaciones hasta entonces incluida en el Juzgado Privativo de Aguas de Orihuela y Pueblos de su Marco, reafirman la preponderancia que adquieren estos sustratos en tanto que son cualidad definidora del territorio, y especifican "como la tierra de dicha huerta es tierra de navas ó almarjalenca, le son indispensables muchos aqüeductos, que reciben las expurgaciones, amarguras y salobres de ellas"3; el texto evidencia la necesidad insoslayable de limpieza y purificación del suelo para hacerlo más productivo.

Las características propias de la geología y edafología imperantes, por una parte, y, las derivadas del clima y dinámica fluvial, por otra, han propiciado la creación de este gran edificio del agua. La Vega de Murcia y la del Bajo del Segura constituyen una región natural que abarca desde el Azud de la Contraparada (presa del siglo IX), entre las pedanías murcianas de Javalí Nuevo y Javalí Viejo, hasta su gola en Guardamar del Segura. Este largo valle-corredor se localiza en el extremo suroeste del continente europeo y en el sureste de la Península Ibérica, dentro del sector oriental del Sistema Bético, en la depresión prelitoral, por tanto, sobre el contacto entre la zona interna y externa de dicho sistema montañoso ${ }^{4}$, una ubicación que justifica también su inclusión en ámbitos climáticos semiáridos.

Si se atiende a la combinación de los principales parámetros, el espacio objeto de estudio puede ser clasificado como estepario seco de verano cálido, con máximos pluviométricos equinocciales y pico principal de otoño según la clasificación de Koppen, mientras que en las que realizan Papadakis y Thornthwaite se corresponderían respectivamente con mediterráneo subtropical seco y semiárido mesotérmico de tercer grado sin exceso de agua ${ }^{5}$. La irregularidad de las precipitaciones genera sequías e inundaciones, dos eventos contrastados a los que debe enfrentarse la llanura murciano-

\footnotetext{
3. Ordenanza Preliminar del Azud de Alfeitamí, 1793

4. Montenat, 1977.

5. Gil Olcina, 1988.
} 
Mapa 2. Recorrido del Azarbe mayor del Norte

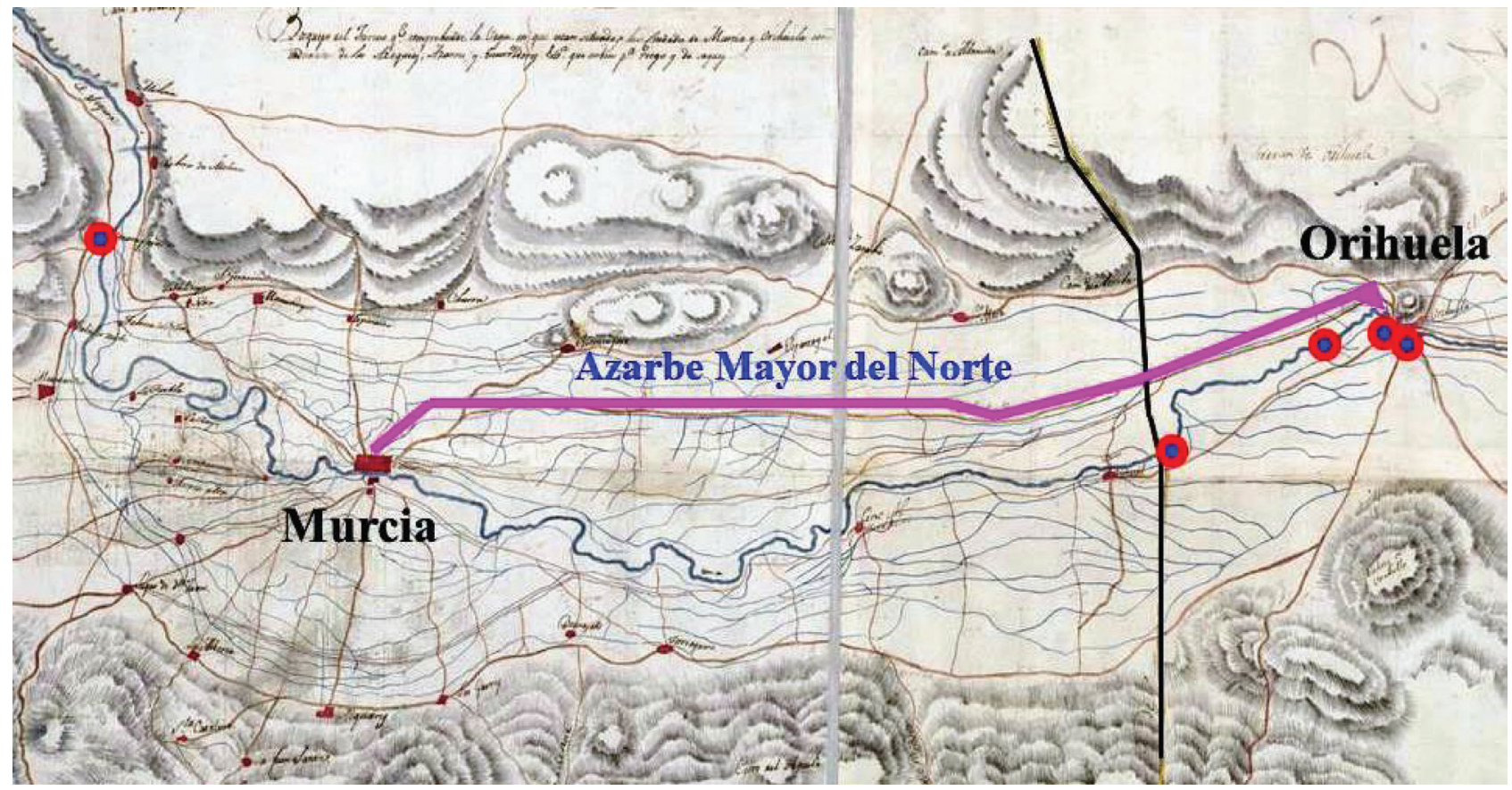

Fuente: Elaboración propia, a partir de la cartografía del Archivo General de la Región de Murcia. Fondo Regional, Servicio geográfico del Ejército, ilustración 22, 1810.

alicantina recorrida por el Segura, donde las infraestructuras hidráulicas contribuyeron, en buena medida, a abordar y paliar estos riesgos; en períodos de escasez, proporcionan la reutilización de los exiguos recursos; en momentos de crecida coadyuvan a laminar la riada.

Los suelos, de formación aluvial, se hallan entre elevaciones no muy altas de origen terciario en su mayoría (Mioceno y Plioceno), con alguna mancha de secundario (Triásico en Sierra de Carrascoy, al sur de Alcantarilla y Murcia, y en las proximidades de Santomera, Orihuela y Callosa del Segura); en general, formaciones ricas en caliza, margas y yesos, lo que explica la elevada presencia de sales que contienen. Sin olvidar, la presencia en el subsuelo, a una cota relativamente alta, de un manto impermeable arcilloso causante de un precario avenamiento que, agudizado en episodios de lluvias torrenciales, conduce a la vega a su antigua condición palustre durante un reducido espacio de tiempo. Se trata de un llano de planitud casi perfecta sin apenas pendiente (inferior al 0,5 por mil), lo que requirió para la puesta en cultivo de un novedoso sistema de riegos fundamentado en una doble circulación de caudales. La red denominada de aguas vivas parte de los azudes o muros de contención transversal al fluir de la corriente para tomar agua del río, a través de una tupida malla de canalizaciones que son las acequias. El sistema se jerarquiza en cuatro niveles, que del superior al inferior se conocen como: acequia mayor, acequia menor o arroba, brazales, para terminar en las regaderas o hijuelas, opciones de vocablo según la demarcación huertana de que se trate.

Esta estructura se dobla en otra inversa, de aguas muertas, si bien, ahora el proceso no es de abastecimiento sino de drenaje; de ahí que el avenamiento principie en los ramales de menor débito o escorredor, que vierte a la azarbeta, esta aboca al azarbe menor (llamado también en Murcia merancho o landrona) para concluir en el azarbe mayor. Este complejo entramado de recepción de caudales constituye un subsistema esencial para entender el funcionamiento de la Huerta, a la vez que se erige asimismo como fuente de suministro hídrico para acrecentar el regadío. Así, la última gran vena de desagüe dirige los volúmenes hacia tres posibles destinos, como son, el propio Segura, otros azarbes más caudalosos o se transforman, a veces, en un determinado punto del cauce, en suministradores de riego, por lo que cambian su función original. La reducción a cultivo del extenso humedal que conformaba el llano de inundación del Segura convertido en feraz Huerta, fue debido sobre todo al protagonismo de la densa red de recogida y evacuación de fluidos de origen diverso, que debieron ser extraídos del subsuelo tras la percolación de las tierras de labor, amén de la acumulación de precipitaciones y escorrentías superficiales que confluyen en ella desde las laderas montañosas. Se trata de un entramado de acueductos proyectados con precisión 
científica que evita se vuelva a la antigua y extensa superficie pantanosa. Si la misión descrita ya es suficientemente notoria, esta alcanza una mayor proyección por el acusado déficit hídrico propio de la Cuenca del Segura, pues permitió la reutilización de las aguas que concentran estos cauces para ampliar el regadío, por ello el nombre dado de aguas de retorno ${ }^{6}$.

\section{Las aguas muertas y sus cauces en las ordenanzas de riego}

La red de abastecimiento hídrico de la Huerta se completa, como se ha indicado anteriormente, con una malla inversa de correspondiente jerarquía, que tras los riegos recoge estos mismos caudales por filtración a través del terreno, de ahí la denominación de aguas muertas tal y como queda expreso en la normativa jurídica de los regadíos de las Huertas de Murcia y de Orihuela; en ocasiones, algunas de estas canalizaciones reúnen los sobrantes de riego, estructurando así todo el sistema. El cometido y nombre de estas categorías de avenamiento se detallan en las Ordenanzas y Costumbres de la Huerta de Murcia en el Capítulo II, artículos $7^{\circ}$ y $11^{\circ}$, de la disposición vigente de 2008 que actualizó las anteriores de 1849 , de la siguiente manera:

\begin{abstract}
"Los cauces de aguas muertas sirven para recibir los avenamientos o escurrimbres de las tierras, descargándolas de la excesiva humedad que les perjudica. Estos son los escorredores, las azarbetas y los azarbes o landronas. Los escorredores reciben los avenamientos de uno o de dos herederos; las azarbetas los de tres o más herederos y los azarbes o landronas son los cauces en que se reúnen dos o más azarbetas. También suele llamarse meranchos o meranchones... Algunos de estos azarbes vienen luego a convertirse en acequias dando riego con sus aguas a otras tierras más bajas. Así se verifica en el azarbe Mayor de la ciudad, en el de Monteagudo, en el del Riacho y en el de Beniel"?.
\end{abstract}

En la demarcación oriolana, las Ordenanzas del Juzgado Privativo de Aguas de Orihuela y Pueblos de su Marco, han conocido un proceso similar de revisión respecto a las de 1836, aprobándose las actuales en 2014. En ellas el Título Preliminar especifica en su artículo $14^{\circ}$ que:

\footnotetext{
6. Canales y Ponce, 2019.

7. Junta de Hacendados de la Huerta de Murcia, 2008.
}

“Hay otros acueductos llamados comúnmente de aguas muertas, que sirven para recibir las espurgaciones, amarguras, salobre y desagües de riego procedentes de las tierras de labor y se denominan escorredores, azarbetas o azarbes menores, y azarbes mayores" ${ }^{\text {. }}$.

Aquí, al igual que los anteriores, cumplen análoga misión, cuya infraestructura se inicia con los escorredores, o arterias de menor tamaño, que vierten al siguiente nivel, cuyas zanjas excavadas a mayor profundidad presentan una secuencia que va aumentando la capacidad de recogida hasta concluir en los azarbes mayores. Estos en el sector oriental de la vega, como fija el artículo $16^{\circ}$ "abocan sus aguas en el río o en otros cauces de la misma naturaleza, o de aguas vivas”, escueta información que no hace justicia a la complejidad y trascendencia del modelo de irrigación.

Los citados colectores presentan tres posibles vías de desagüe: al propio curso fluvial, que incrementa así sus volúmenes, disponibles nuevamente para el riego en su tramo final; a otras conducciones homólogas, que resultan imprescindibles en el territorio, en origen almarjalenco, y que requiere múltiples conexiones para asegurar una plena evacuación y la disminución del nivel freático en pro de la agrarización; finalmente, el propio cauce puede cambiar de función o bien ramificarse mediante acequias, opción que requiere una matización. El enunciado a priori conduce a pensar que llegan a un canal de riego que deriva directamente del río, sin embargo, el propio fluido avenado se convierte a "aguas vivas", pues cambia de función y su cometido ahora es regar. Son ejemplos, en Orihuela, la Acequia de las Puertas de Murcia que nace del murciano Azarbe Mayor del Norte, siendo por consiguiente su cola, y la Acequia de Mudamiento, continuación del Azarbe de Millanares.

El rasgo distintivo de este regadío histórico es la doble función -drenaje/riego- en cauces de avenamiento, como el Azarbe Mayor del Norte ${ }^{9}$, exponente de las relaciones que se establecen entre los grupos humanos y el medio, para salvar los obstáculos que este les impone. En este caso, son los condicionamientos que supone un clima semiárido y la escasez de recursos hídricos que lo caracterizan. El acueducto es uno de los ejes hidráulicos que muestra la idiosincrasia de una región natural dividida administrativamente en los albores del

\footnotetext{
8. Juzgado Privativo de Aguas de Orihuela y Pueblos de su Marco, 2014.

9. Cauce avenante que nace al este de la ciudad de Murcia y concluye en el Segura, en las inmediaciones de Orihuela. Los círculos indican el emplazamiento de los azudes medievales citados en los libros de repartimento de tierras tras la conquista cristiana (Mapa 2).
} 
siglo XIV, tras la Sentencia Arbitral de Torrellas (1304) y el posterior Acuerdo de Elche (1305), por los que la Huerta de Murcia se queda en la Corona de Castilla y la de Orihuela pasó a incorporarse a la de Aragón.

A su vez, es paradigma del saneamiento y posterior colonización de una amplia zona pantanosa interfronteriza, de carácter endorreico, donde moría la red de drenaje inicial de la margen izquierda del Segura. Las necesidades de desecación son las responsables de las sucesivas ampliaciones que conoció esta arteria de avenamiento, pues ante los escasos débitos hidrológicos la sociedad encontró una solución de gran eficacia para el aprovechamiento de todos los volúmenes de diversa procedencia allí concentrados (lluvias, ramblas, manantiales, y sobre todo las provenientes de las filtraciones de las tierras de labor) convirtiéndose en fuente de suministro para acequias menores, conforme su canalización se fue prolongando y ramificando, incorporó a la función original la de regar.

Este atributo se observa ya en la parte central de su trazado, donde arranca la Acequia Nueva del Raal, por el costado derecho, y a escasos metros por la ribera opuesta la Acequia de Pitarque, que comienza en las inmediaciones del Carril de las Juanas; continúa el citado azarbe con el cometido de riego, aunque sin cambiar de nombre, pues alimenta mediante partidores en ambos márgenes, con toma madre o directa (es decir, mediante compuertas laterales en sus quijeros), las tierras colindantes casi hasta el límite interprovincial -la Vereda del Reino, frontera histórica entre los municipios de Murcia y Orihuela- cuyo extremo final penetra en esta última dando lugar a la Acequia de las Puertas de Murcia, que termina en el Segura al oeste de la ciudad en las inmediaciones del Centro Comercial Ociopía. Se trata por consiguiente de un eje de vital importancia por la destacada doble naturaleza que desempeña en el regadío, cuya organización supuso la decidida colaboración de ambas administraciones locales y los respectivos heredamientos de regantes para lograr el efectivo vaciado del área alagada y puesta en cultivo de unos terrenos con cota inferior al curso del río.

El logro de nuevas superficies productivas conllevó la necesidad de crear las infraestructuras de drenaje oportunas para evitar el endémico encharcamiento que reproducen de forma insistente subsistemas idénticos al modelo general descrito, como se advierte con la construcción de los meranchos del Norte y de Gil (equivalentes a azarbes menores). Sendos cauces discurren a ambos lados y en paralelo al Azarbe Mayor del Norte, para converger estos en el Mancomunado, gran acue- ducto avenante surgido en tierras oriolanas con terminación en el río, incrementando los recursos hídricos circulantes, previo al Azud de los Huertos, en donde se repite la redundante secuencia definidora del paisaje huertano, riego-drenaje/drenaje-riego. El patrón que representa el colector seleccionado, objeto de análisis, es fruto de un dilatado proceso de transformación territorial que culmina en el siglo XVII, aunque con notables mejoras en las siguientes centurias. Se erigió como ejemplo durante el setecientos para proseguir la colonización de esta llanura aluvial en el sector más deprimido próximo a la desembocadura del Segura, empresa de extraordinaria amplitud promovida por Luis Belluga y Moncada, obispo de Murcia.

Por último, conviene subrayar que las locuciones específicas de merancho y landrona se dan únicamente en la parte oriental de la vega murciana, el sector más tardío de saneamiento y colonización, cuya desecación se inicia en 1548 -La Urdienca- y en 1590 -El Raal ${ }^{10}$ - donde confluyen la trascendencia de la tierra y el valor del agua como elementos físicos que, con el paso del tiempo y la intervención de los grupos sociales, se consiguió doblegar una naturaleza inhóspita para ponerla a su servicio. Por lo tanto, estos topónimos aparecen en las pedanías del término municipal de Murcia: Cabezo de Torres, Santiago y Zaraiche, Monteagudo, Nonduermas, Puente Tocinos, Torreagüera, San Benito, El Raal, Alquerías, y Santa Cruz, además del municipio de Santomera, que en 1978 alcanzó su independencia del anterior ${ }^{11}$. Hay que puntualizar que algunas de estas demarcaciones son limítrofes con la oriolana y sin embargo en esta no se utilizan las referidas denominaciones.

\section{El Azarbe Mayor del Norte, cauce distribuidor de riego en la Huerta}

Al nordeste de la ciudad de Murcia existía de antiguo un espacio endorreico en la actual pedanía de Zarandona, originado por diversas fuentes de suministro hídrico, al estar alimentado por las filtraciones del regadío y las inundaciones del Segura, de ahí que el barrio contiguo de reciente construcción mantenga el topónimo de La Flota; allí abocaba el Azarbe del Papel, que nacía en La Albatalía en las cercanías del Carril de los Uña y discurría, incorporando previamente el Azarbe de la Cruz. Además, en dicho lugar se concentraban las percolaciones de las tierras regadas por la Acequia de Aljufía, gran

\footnotetext{
10. Calvo, 1982.

11. González y García, 1998.
} 
ramal de riego que recorre la parte septentrional de la Huerta de Murcia y que deriva las aguas caballeras del río en el Azud de la Contraparada. La densa red de drenaje de este sector huertano confluye en tres grandes colectores, siendo el más importante el Azarbe Mayor del Norte, con $12 \mathrm{~km}$ de recorrido, continuación del anterior donde toma su nombre en El Molino del Batán y se sitúa entre los meranchos del Norte y del Gil, ambos con una extensión de $8 \mathrm{~km}$. En origen, estos tres cauces convergían en el almarjal de La Urdienca, paraje murciano situado entre el río y Santomera, cuya lámina de agua se encontraba a más profundidad que la solera del Segura, de ahí que la única vía posible de evacuación fuera por tierras de Orihuela.

Este humedal se prolongaba en la demarcación oriolana, por lo que ambas ciudades estaban interesadas en su erradicación, para ello fue preciso crear una gran infraestructura hidráulica que tiene en el paraje de Los Tres Puentes su núcleo neurálgico, dado que allí se juntaban los aludidos meranchos, por lo que se tuvo que abrir el Mancomunado, conocido también en estas tierras alicantinas como el Reguerón, que vierte las aguas al río Segura. A su vez fue preciso construir la Canal del Perillo para que el Azarbe Mayor del Norte cabalgara sobre el Merancho del Norte y diera lugar a la Acequia de las Puertas de Murcia; con estas actuaciones ingenieriles se consiguió la desecación global del territorio, así como un intenso proceso de agrarización. La continuidad de estos cauces ha creado desde un punto de vista fisiográfico un socioecosistema donde la acción humana es vital para entender la configuración de este paisaje de agua. La conectividad de estos espacios es fruto del consenso histórico logrado entre los entes rectores del regadío -la Junta de Hacendados de la Huerta de Murcia y el Juzgado Privativo de Aguas de Orihuela- que ha originado ambos espacios en simbiosis, aunque administrativamente el límite fronterizo entre las coronas de Castilla y Aragón, es decir, entre los reinos de Murcia y Valencia, lo constituye la Vereda del Reino, linde histórico que ya quedó establecido en la mencionada Sentencia Arbitral de Torrellas de 1304.

El territorio mostraba en época medieval unas características comunes a sendos lados de la raya divisoria, como eran la presencia de terrenos encharcados, que suponían un grave peligro para la salud pública al ser un foco de infecciones palúdicas. Estos almarjales ya están documentados en los libros de los repartimientos de tierras de Murcia y Orihuela, realizados después de la conquista cristiana. Al tratarse de terrenos margina- les en la periferia de la Huerta, de difícil cultivo y suelos más pobres, fueron los últimos que se entregaron. Estos espacios anegados representaban un paisaje mutante que fluctuaban con las estaciones a lo largo del año en virtud de las condiciones meteorológicas, amén de los aportes derivados de las riadas y de las surgencias salinas que allí se localizaban dando lugar a amplias extensiones de saladares.

En el estudio sobre el Repartimento de Murcia ya se cita en la quinta partición, iniciada en 1272 y concluida al año siguiente, la existencia de azarbes en el sector septentrional de la Huerta de Murcia, en él aparece explícitamente nombrado el Azarbe de Monteagudo, con motivo de la adjudicación de 300 tahúllas de tierra que el rey castellano, Alfonso X el Sabio, asignó a Guillén de Narbona:

\footnotetext{
"Mando el Rey dar emienda a Guillem de Narbona de c atafullas que don Gil Garçez et sus companneros li auian tomado, et porque los heredamientos eran partidos quando el Rey li mando dar emienda, non fallamos terra que le diessemos sinon un amarjal que era fincada de todas las particiones, que es entre la quadriella de Godiaçibit et el açarue de Montagut et del termino de la Reyna, fasta la açaure mayor, ccc atafullas si las ouiere $^{12 "}$
}

Una centuria después, en 1329, está documentado que muchas tierras de almarjal estuvieran sin dueño y su extensión aumentase debido a la disminución demográfica que dejó abandonada la red de riego con la consiguiente pérdida de los rendimientos agrarios. Este proceso ha sido analizado en profundidad por Martínez Carrillo (1997) quien indica cómo en los albores del siglo XV el regente don Fernando daba permiso a Murcia para que el marjal de Monteagudo fuese repartido y poblado, de forma que en 1410 la ciudad ordenaba su desecación "para que se pueda labrar". A partir de entonces se llevaron a cabo obras de reconstrucción, ensanchamiento y prolongación del cauce del llamado Azarbe de Monteagudo que contó en un principio con la oposición firme por parte de los agricultores de Orihuela, puesto que esta evacuación elevaba el nivel de las aguas en sus tierras.

Esta circunstancia condujo al acuerdo adoptado entre ambos concejos de continuar el acueducto por tierras oriolanas, con sendas participaciones de capital y mano de obra. Así, entre 1413 y 1416 se completa el

\footnotetext{
12. Torres Fontes, 1960.
} 
viejo cauce con otro de nueva creación que se corresponde en la actualidad con el Azarbe Mayor del Norte ${ }^{13}$. Infraestructura que debía posibilitar el proceso de colonización agrícola, tras superar dos obstáculos, por una parte, el precario drenaje y la falta de limpieza del canal en todo su recorrido, hecho que no siempre fue posible, pues los suelos ganados para la agricultura no dispusieron de un avenamiento efectivo; por otra, el desinterés de los grandes hacendados beneficiados con la privatización de tierras, ante otras actividades económicas más rentables en la zona, como eran, los pastizales para un aprovechamiento ganadero; la obtención de sosa a partir de la recolección silvestre de la barrilla y la pesca de anguilas, cuyo arrendamiento resultaba lucrativo y originaba, además, obstáculos en el discurrir de las aguas.

La reducción del almarjal fue una constante preocupación del concejo murciano, una fecha significativa que conviene destacar es el año 1510, cuando se retoma, nuevamente, este empeño por el regidor Pedro de Perea al autorizar la corona castellana las obras necesarias para bonificar los terrenos alagados. El siguiente fragmento del citado documento describe la situación y las causas que el área pantanosa originaba, al precisar que:

"En la vega de dicha çibdad, al cabo de la huerta della, hasta juntar con el termino de la dicha çibdad de Orijuela, ay, unas tierras llenas de agua e carrizales que dizen almarjales, en los cuales se recoge el agua que se escurre de las açequias de la dicha huerta, e por non aver en ella los escorredores e sangreros necesarios e por ser muy hondas, non se siembran nin se aprovecha persona alguna de ellas"14.

Aunque las intervenciones realizadas resultaron deficientes y poco duraderas prevaleció siempre la idea de lograr el saneamiento integral, circunstancia que se demoraría hasta finales del siglo XVII con lo que se va a lograr la puesta en cultivo del extenso almarjal que se extendía por los partidos de Monteagudo, La Urdienca, El Campillo y Santomera, ampliado a comienzos de la siguiente centuria por El Raal, localizados en la parte nororiental de la Huerta de Murcia en contacto con la de Orihuela (Mapa 3).

\footnotetext{
13. Arteria que sirvió para desecar el almarjal septentrional de las Huertas de Murcia y Orihuela, concebida para el avenamiento y que en los dos puntos señalados con un círculo en su recorrido se convierte en suministradora de riego (Mapa 3).

14. Torres Fontes, 1992.
}

Las roturaciones que permiten la ampliación del espacio regado se orientan hacia dos ámbitos topográficos de condiciones opuestas, que requieren en ambos casos la creación de conducciones hidráulicas para la distribución de caudales. Se trata del secano, que ocupa las vertientes meridionales de los cabezos que delimitan la planicie aluvial por el norte, transformado gracias al uso de artefactos elevadores de agua que alimentan dichas canalizaciones; en contrapartida, se encuentra el gran marjal, rescatado mediante la construcción de una malla dendrítica de acequias que van extendiéndose por el valle aprovechando su pendiente natural hacia tierras oriolanas. Este avance se dificulta debido al problema de elevación de la capa freática conforme desciende la cota, y a la necesidad de evacuar las aguas muertas por medio de una densa red de azarbes, que en este sector pasan a denominarse meranchos, lo que denota un origen más reciente, una identificación que no aparece ni en el heredamiento sur murciano, ni en el paisaje huertano del Bajo Segura.

La situación descrita se presenta a priori como un inconveniente $\mathrm{y}$, sin embargo, por el ingenio de la población frente a las limitaciones que impone el medio para la colonización, este hándicap deviene en oportunidad, al aportar nuevos recursos hídricos que son empleados para el riego. Es de reseñar la doble actuación realizada que consigue este objetivo; por un lado, se produce el desagüe al río; y por otro, la ramificación de arterias de avenamiento que incorporan a su función original la de riego, lo que justifica que se las nombre como acequias. Ambas operaciones son coetáneas y representan significativos hitos ingenieriles que suponen fuertes inversiones, a la vez que proyectos técnicos viables y eficaces para su realización, lo que requiere contar con elites de poder, tanto social como financiero, además de profesionales cualificados. Los ejemplos seleccionados son buena muestra de ello, a la vez que exponentes representativos de colectivos - público y privado- con capacidad para emprender estas intervenciones de amplia repercusión territorial, pues la primera tiene como propósito la evacuación y merma del humedal; mientras que la segunda, aspira a incrementar los espacios de producción con la extensión del regadío. 
Mapa 3. Cambio de función drenaje-riego en el Azarbe Mayor del Norte

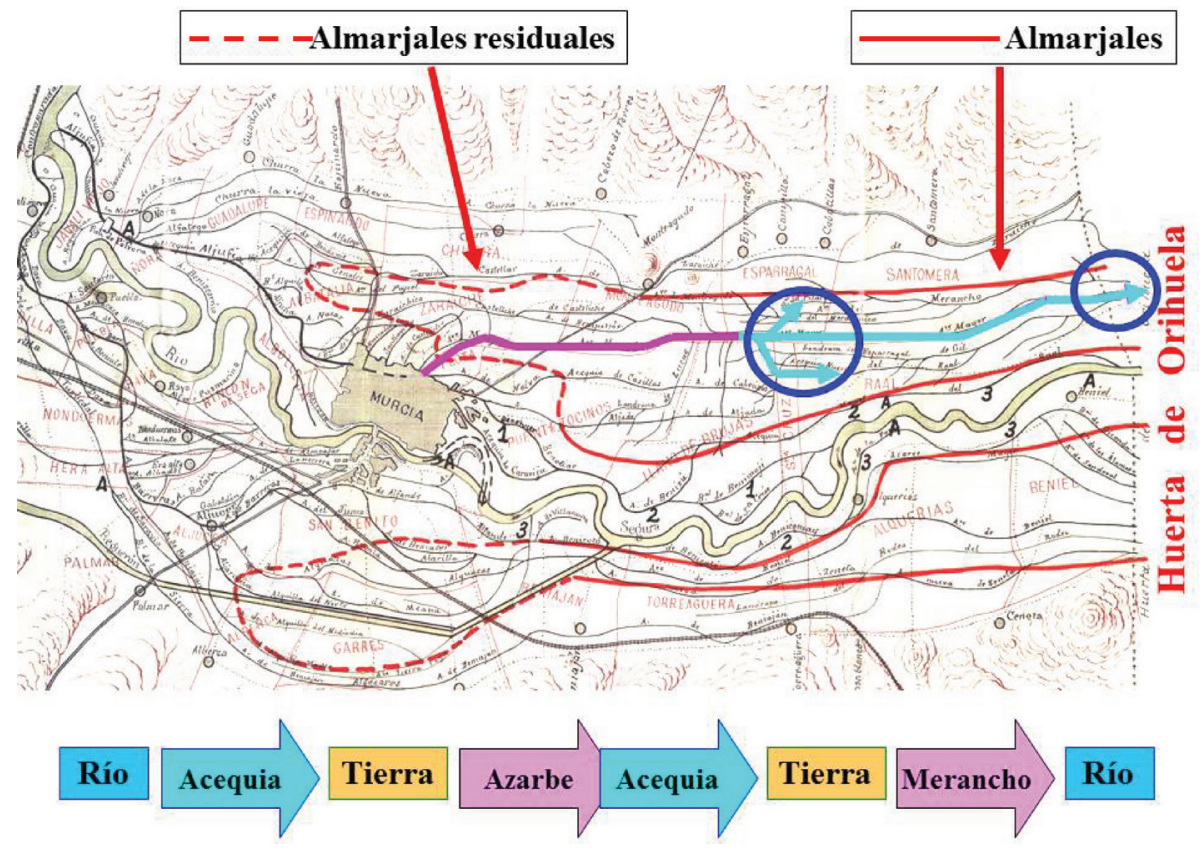

Fuente: Elaboración propia a partir de la cartografía de Martínez Carrillo, 1997.

\section{La erradicación del almarjal y la ampliación del regadío}

Los concejos de Murcia y Orihuela retomaron en 1685 el viejo anhelo de eliminar la zona encharcada que afectaba a ambos en la línea fronteriza y, de esta forma, solventar definitivamente el problema. Años después, se firmó el acuerdo que contemplaba las infraestructuras que debían realizarse para desaguar los terrenos, convenio divulgado con satisfacción puesto que conllevaba grandes ventajas para sendos heredamientos huertanos. En el escrito de 1688 se podía leer:

"A esta parte concurren gran cantidad de aguas a la Azarbe Mayor de esta ciudad, que por no tener bastante buque y caída están retenidas ocupando mucho número de tierras, lo que ha ocasionado que todos los moradores y herederos de aquellos parajes están con muchos achaques originados por los vapores que exhala esta retención de agua, privándoles del beneficio de las tierras, que no pueden cultivarse ni percibir fruto de ellas; y aunque algunos años que han sido faltos de lluvias, en que han sido menos estas aguas muertas, lo que quedaba en seco, alentara a cultivarlo y sembrarlas a mucha costa con la esperanza de lograr fruto. Después sobrevenían lluvias y avenidas que inundaban muchas tierras y quedaban frustradas las cosechas y después de esto perdido el gasto que se había hecho lo que ha desalentado mucho a los dichos herederos de ambas ciudades y a que dichos vapores están amenazando de muchas enfermedades que puedan pasar a contagiosas"15.

Del texto se desprende que los alicientes que animaban la bonificación eran tanto de carácter agrícola como sanitario, aspectos que redundaban en favor de los dos municipios, empeñados en encontrar una vía de salida a las aguas que anegaban ese territorio. En el término de Orihuela se realizaron dos actuaciones significativas, de distinto signo, por un lado, la construcción de un gran cauce avenante, llamado el Mancomunado, al que se hace confluir los azarbes del Merancho del Norte y del Merancho del Gil ${ }^{16}$, para a lo largo de $3 \mathrm{~km}$ de longitud verter sus aguas al Segura; es, por tanto, el colector clave para conseguir el objetivo determinado. Por otro, la creación de la citada infraestructura requirió obras de mejora y consolidación en el Azarbe Mayor del Norte, al ser necesario proyectar aquella por debajo de este, donde el mismo cumplía funciones de riego, la solución fue la realización del Canal del Perillo. Se trata de una fábrica de sillería que conecta la cola del citado azarbe con la Acequia de las Puertas de Murcia, y configura uno de los encabalgamientos más característicos y determinantes, sobre todo en los sectores más deprimidos de la llanura aluvial.

\footnotetext{
15. Vázquez, 2014.

16. La infraestructura refleja la complejidad del gran edificio del agua y su funcionamiento al actuar como un subsistema dentro del conjunto hidráulico general (Mapa 2).
} 
Las ventajas de la operación redundaban en beneficios comunes, para Murcia suponía culminar la ansiada erradicación del marjal, a la vez que ampliar el espacio agrícola; Orihuela, además de conseguir estas mismas ganancias incrementaba los recursos hídricos para su regadío, al recibir el Segura nuevos caudales previos al Azud de los Huertos, segunda presa del regadío de la ciudad; toda vez que, al sobrevolar el Canal del Perillo el Merancho del Norte encontraba una nueva vía de abastecimiento para la Acequia de las Puertas de Murcia ${ }^{17}$. Esta arteria por ser continuidad del Azarbe Mayor del Norte quedaba supeditada únicamente a los volúmenes que le podían llegar pues es la cola de ese eje, lo que implicaba eliminar esta dependencia, al captar más aguas muertas provenientes del cauce que atraviesa la citada canal. Se encontró así una nueva fuente de suministro con una sencilla técnica, que consistió en abrir una ventana lateral o albellón en su caja para recibir los fluidos cuando se producía el entablado, una maniobra para atajar la corriente que circulaba por la parte inferior y elevarla - hacer rafa- hasta que alcanzara el nivel del aludido vano por donde salir. No obstante, la estructura creada provocaba otras disfunciones que motivaron enfrentamientos entre los heredamientos vecinos, hasta lograr un desenlace definitivo en el último cuarto del siglo XX.

En la ampliación del regadío contribuyeron decididamente los grandes propietarios de la zona, entre ellos es de destacar la gestión realizada por el clero regular, sobre todo jerónimos y jesuitas. A ellos se debe la apertura de las acequias de Pitarque y Nueva del Raal, respectivamente (Figura 1). La Orden Jerónima se estableció en Murcia en 1579 al recibir un rico legado que les dejara el gran hacendado Alonso Vozmediano de Arroniz ${ }^{18}$. Entre los bienes cedidos se hallaban tierras pendientes de panificación, como era un extenso predio en el pago de La Urdienca que abarcaba desde La Cueva (Monteagudo) hacia El Esparragal y Santomera. El interés de los religiosos por fomentar la agricultura, junto a otros titulares, motivó que estos suelos empantanados fueran saneados al promover la irrigación del sector huertano oriental, mediante la construcción de un partidor, proyectado y realizado por Melchor Luzón, que derivara aguas del Azarbe Mayor del Norte, lo que significó un importante avance de las roturaciones. Las explicaciones reflejadas por el autor en el expediente de encargo verifican el do-

\footnotetext{
17. Estructura de la red de riego-avenamiento que posibilito la evacuación del antiguo marjal común a los municipios de Murcia y Orihuela (Figura 3).

18. Sánchez Baeza, 1983.
}

Figura 1. Sector del Azarbe Mayor del Norte donde se inicia el Riego

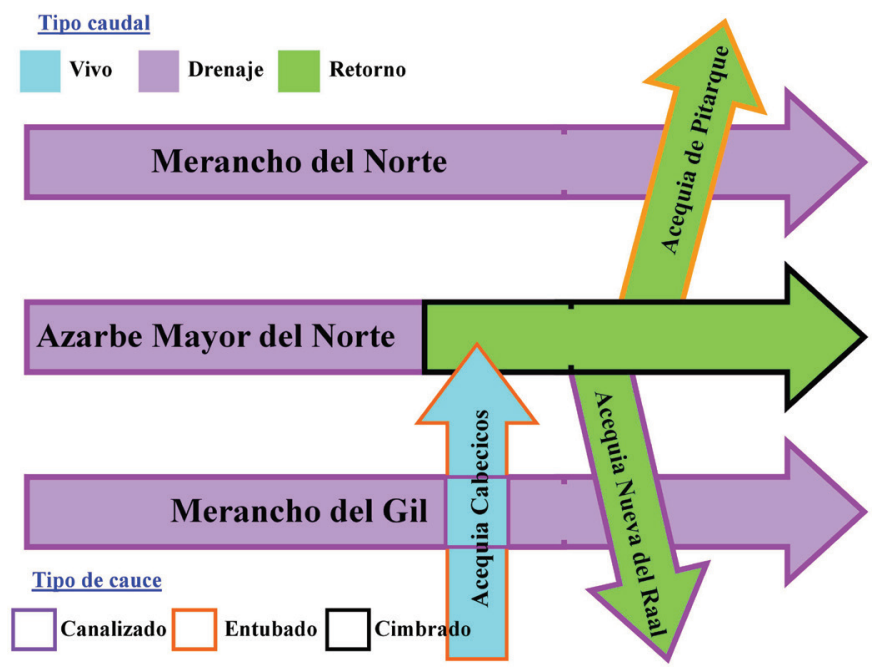

Fuente: Elaboración propia a partir del trabajo de campo.

minio que poseía, no sólo como arquitecto, sino también, en la realización de obras hidráulicas, pues detalla que:

\begin{abstract}
"Corrió el nivel desde el puesto que se ha de hacer dicho partidor en distancia de setecientas y treinta y ocho varas que hay desde la toma hasta el primer portillo de las tierras que ha de regar y ha hallado por dicho nivel tener las aguas suficiente caida y corriente para su riego con la tercia de altura de dicho partidor sin que el agua que entrare por el portillo se vuelva a la madre por tener el suelo del brazal un palmo menor que el suelo de dicho azarbe, y con dicha tercia de altura que han de subir las aguas no tienen lugar de volverse a su madre; y para que Vuestra Señoría pueda ver la forma que ha de tener dicho partidor exhibe la planta adjunta que tiene hecha de él para su mayor claridad; todo lo cual dice ha puesto en ejecución y lo ha nivelado como tal maestro y según su saber y entender"19.
\end{abstract}

La heredad bonificada por los frailes con esta infraestructura abastecía una superficie de 3.160 tahúllas $-353,2880$ ha $-{ }^{20}$, que más tarde sería entregada a censo a los colonos, quienes llevarían a cabo el acondicionamiento del terrazgo y la creación de la red privada de riego y avenamiento. El éxito de la operación motivó que años después la Compañía de Jesús, con propiedades en la margen derecha del Azarbe Mayor del Norte, solicitara igualmente la apertura de un nuevo ramal para sanear sus tierras. A finales de noviembre de 1701 el Concejo de Murcia concedió licencia para abrir la boquera que dio origen a la Acequia Nueva del Raal, emplazada aprove-

\footnotetext{
19. Luzón, 1697.

20. Belmonte, 2015.
} 
chando el mismo partidor de donde surgía Pitarque, denominado este de los Jerónimos o de los Frailes y cuyo trazado se proyectaba en sentido opuesto. La realización del citado partidor fue efectiva una vez superados los recelos que mantenía el heredamiento de la Acequia de Casillas, cuya cola desaguaba en el mencionado azarbe, por considerar que el regolfo que podía producir el ataje afectaría a las tierras al obstaculizar el fluir normal de las aguas, así como su avenamiento.

Dos décadas después en aras de buscar una solución definitiva se propuso el cambio de emplazamiento para esta toma, que fue adelantada unos doscientos metros, ante la diferencia de cota que recorrerían ambos cauces. El impulso que la colonización cobró una vez superada la Guerra de Sucesión, se refleja en la valoración realizada en 1739 por Pedro Tomás Ruiz, sobreacequiero de la Huerta, quien afirmaba en solicitud dirigida a las autoridades municipales el "aumento de los riegos de más de diez mil tahullas" en estos parajes ${ }^{21}$. Para ese año la Acequia Nueva del Raal regaba un total de 3.530 tahúllas $^{22}$.

\section{Situación actual de los cauces para riego de naturaleza avenante}

La seña de identidad que otorga mayor trascendencia a la infraestructura hidráulica de las Huertas de Murcia y Orihuela es la existencia de cauces de riego que no se abastecen directamente del río a través de los azudes, sino que proceden de canalizaciones de aguas muertas que, al derivarlas, reciben el nombre de acequias; incluso se da la circunstancia de que el propio acueducto drenante en algún trazado de su recorrido, mediante paradas, se convierte igualmente en proveedor de caudales para las tierras colindantes. Una función que desempeña el colector analizado -Azarbe Mayor del Norte-cuya realización fue clave para ampliar el regadío a finales del siglo XVII y principios del XVIII, una vez desecado el marjal septentrional que compartían ambas ciudades. Es de destacar la gran cuenca receptora de este eje de avenamiento, como se detalla en la Tabla 1, dado que recibe los sobrantes de algunas acequias (Casillas y Casteliche); igualmente, a él van a parar la cola de los brazales (Ponta, Cabrera y de los Poceros); asimismo, las filtraciones del riego a manta que aportan diversas landronas y más recientemente, concentra volúmenes tratados por la Depuradora Murcia Este, sita en el paraje Rincón del Gallego.

\footnotetext{
21. Calvo, 1982

22. Barranco y Herrero, 1996.
}

TABLA 1. CANALIZACIONES QUE ABASTECEN AL AZARBE MAYOR DEL NORTE

\begin{tabular}{lll}
\hline CAUCE & FUNCIÓN & MARGEN \\
\hline Cola Acequia de Casillas & Riego & Derecha \\
\hline Depuradora Rincón del Gallego & Riego & Derecha \\
\hline Landrona del Cementerio & Drenaje & Derecha \\
\hline Landrona de lo Canal & Drenaje & Derecha \\
\hline Azarbe Anquijanes & Drenaje & Derecha \\
\hline Landrona Hondo de Casillas & Drenaje & Derecha \\
\hline Acequia de Casteliche & Riego & Izquierda \\
\hline Azarbe de Pozuelo & Drenaje & Izquierda \\
\hline Brazal de Ponta & Riego & Izquierda \\
\hline Azarbe de la Estacada & Drenaje & Izquierda \\
\hline Landrona de Basilio & Drenaje & Derecha \\
\hline Brazal Cabrera & Riego & Derecha \\
\hline Landrona de la Parra & Drenaje & Derecha \\
\hline Brazal de los Poceros & Riego & Derecha \\
\hline
\end{tabular}

Fuente: Cartografía digitalizada (consulta 2019). Junta de Hacendados de la Huerta de Murcia.

La idiosincrasia de esta importante infraestructura de drenaje, en la parte septentrional de la Huerta de Murcia, estriba en que, debido al gran volumen de filtraciones que recibe, se convierte en fuente de suministro de aguas vivas para acequias menores (Tabla 2). Como son, en la parte central de su trazado, la Acequia Nueva del Raal, por el costado derecho, y a escasos metros por la ribera opuesta la Acequia de Pitarque, que arranca en el Carril de las Juanas; continúa el citado azarbe con su función de riego y sin cambiar de nombre alimenta con tomas madre las tierras colindantes en ambas orillas, casi hasta el límite interprovincial, cuya cola penetra en la demarcación oriolana dando lugar a la Acequia de las Puertas de Murcia, y finaliza en el Segura, al oeste de Orihuela, antes de que se introduzca en la ciudad (Figura 2). Esta arteria de avenamiento, suministradora de riego constituye un nexo entre ambas Huertas y se erige como paradigma en la dinámica de ampliación del regadío, a costa del retroceso del almarjal mediante el empleo de los caudales que contiene, en su misión de lavar-fertilizar el suelo, durante las sucesivas prolongaciones o derivaciones de canalizaciones realizadas en la vega hacia la desembocadura del río.

Los problemas que planteaba un territorio con escasa pendiente, hacía preciso, con anterioridad a su puesta en riego, solucionar la evacuación de las aguas someras que allí se estancaban, situación que se resolvió a través de la conexión entre cauces de drenaje 
Figura 2. Tramo final del Azarbe Mayor del Norte donde se convierte en Acequia

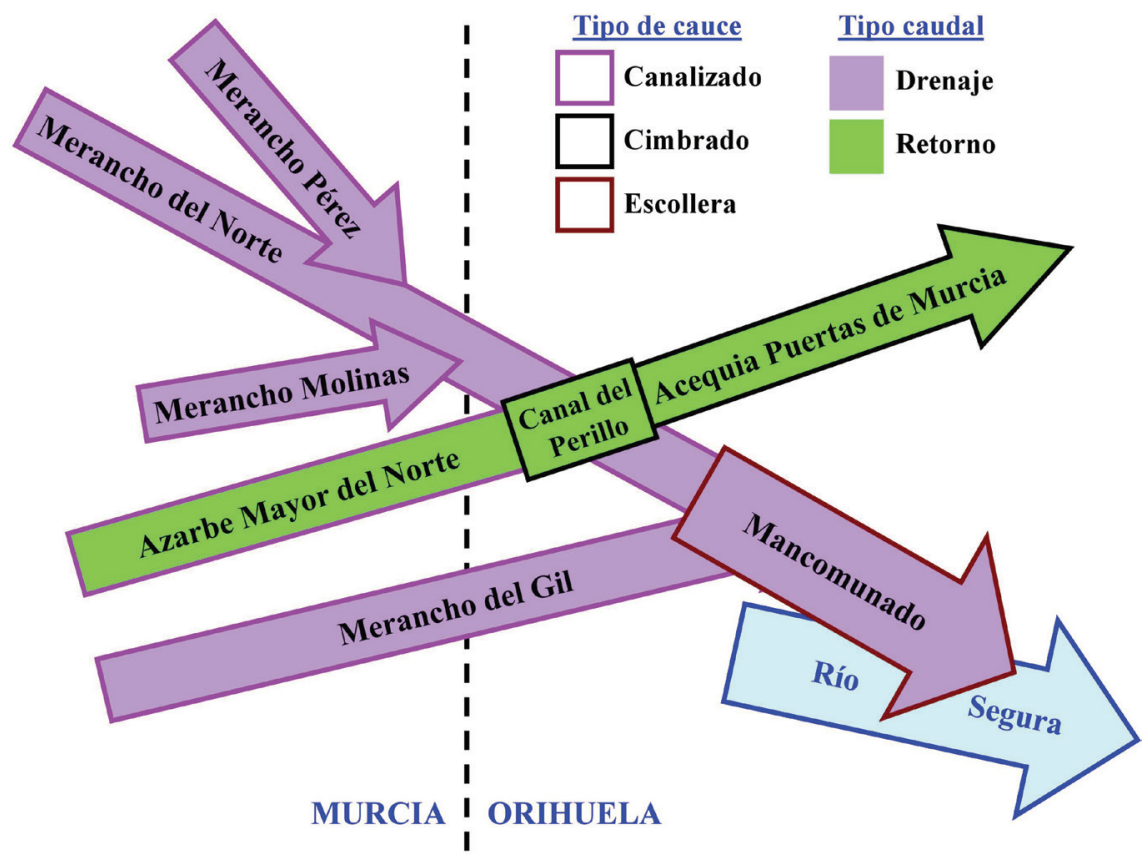

Fuente: Elaboración propia a partir del trabajo de campo.

TABLA 2. DERIVACIONES DE RIEGO EN EL AZARBE MAYOR DEL NORTE, 2019

\begin{tabular}{lll}
\hline TIPOLOGÍA & $\begin{array}{l}\text { UBICACIÓN } \\
\text { (partidor) }\end{array}$ & $\begin{array}{l}\text { INICIO } \\
\text { (en el cauce) }\end{array}$ \\
\hline Acequia Nueva del Raal & Derecha & $5.206 \mathrm{~m}$ \\
\hline Acequia de Pitarque & Izquierda & $5.424 \mathrm{~m}$ \\
\hline $1^{\text {a Parada Azarbe Mayor del Norte }}$ & Central & $6.854 \mathrm{~m}$ \\
\hline Parada final Azarbe Mayor del Norte & Central & $11.744 \mathrm{~m}$ \\
\hline Acequia de las Puertas de Murcia* & Central & $11.980 \mathrm{~m}$ \\
\hline
\end{tabular}

Fuente: Información facilitada por Alejandro Aracil Orenes. Junta de Hacendados de la Huerta de Murcia.

*Acequia de las Puertas de Murcia tiene un recorrido de riego de 6.321 $\mathrm{m}$ y termina en el río Segura antes de que este atraviese la ciudad de Orihuela.

para lograr erradicar el aguazal. Esta circunstancia se hace evidente al analizar el itinerario máximo del eje de salida de estos caudales pues, desde el noroeste de la ciudad de Murcia, ya es necesario iniciar las obras de desecación de los suelos pantanosos mediante la apertura del Azarbe del Papel, que nace a $46 \mathrm{~m}$, e incorpora a mitad de su recorrido el Azarbe de la Cruz, para abocar en el Azarbe Mayor del Norte, transcurridos casi cinco kilómetros, con un desnivel óptimo en este trayecto del 2,25 por mil. Muy diferente es la trayectoria que sigue este último colector emplazado en la zona más deprimida como era el antiguo paraje La Urdienca-El Raal, por cuanto con una longitud próxima a los doce kilómetros, muestra pendientes ínfimas del 0,58 y 0,41 por mil
(Tabla 3), en un sector donde parten las acequias Nueva del Raal y Pitarque, además de cumplir el mismo funciones de riego. El saneamiento de este sector de avenamiento-riego requirió complejas obras hidráulicas pues fue necesario realizar una densa red de drenaje a mayor profundidad, que dio lugar a una proliferación de encabalgamientos o cruces de canalizaciones a dos alturas, para buscar siempre la circulación de los caudales por gravedad. En todo este entramado la implicación de los regantes oriolanos resultó decisiva pues con la construcción de la Acequia Puertas de Murcia se conseguía alcanzar una mayor inclinación, lo que facilitaba una salida más rápida de los caudales al río, como se observa en los declives de los dos últimos tramos de este emisario con los valores 4,24 y 2,21 por mil.

Los encabalgamientos en el trazado hidráulico son obras cada vez más frecuentes a medida que se pierde cota, por ello dominan en la zona de estudio (Tablas 4 y 5). En la revisión realizada de la cartografía digital de la Junta de Hacendados de Murcia, se ha podido localizar un total de 21 canales a dos alturas, siendo los más numerosos los existentes en la Acequia Nueva del Raal con 15 de ellos, dado que sus tierras se hallan a menor altitud. Este rasgo hace que incluso la propia red de avenamiento se superponga a otra homóloga. Es de destacar, cómo en este sector de Huerta las acequias se construyen sobre la densa malla de drenaje que recibe la denominación específica de landronas o meranchos, situación que contrasta con el nombre de 
TABLA 3. EJE LONGITUDINAL DEL AZARBE MAYOR DEL NORTE CON SUS PENDIENTES, 2019

\begin{tabular}{|c|c|c|c|c|c|}
\hline CAUCE & LONGITUD (m) & $\begin{array}{c}\text { INICIO } \\
(\mathrm{m})\end{array}$ & $\begin{array}{l}\text { FINAL } \\
(\mathrm{m})\end{array}$ & PENDIENTE (\%) & DESAGÜE \\
\hline Azarbe del Papel* & $4.883^{\star \star}$ & 46 & 35 & 2,25 & $\begin{array}{l}\text { Azarbe Mayor } \\
\text { del Norte }\end{array}$ \\
\hline Azarbe Mayor del Norte & 6.854 & 35 & 31 & 0,58 & $\begin{array}{l}\text { Azarbe Mayor } \\
\text { del Norte } \\
\text { (aguas vivas) }\end{array}$ \\
\hline $\begin{array}{l}\text { Azarbe Mayor del Norte } \\
\text { (aguas vivas) }\end{array}$ & 4.890 & 31 & 29 & 0,41 & $\begin{array}{c}\text { Azarbe Mayor } \\
\text { del Norte } \\
\text { (aguas muertas) }\end{array}$ \\
\hline $\begin{array}{l}\text { Azarbe Mayor del Norte } \\
\text { (aguas muertas) }\end{array}$ & 236 & 29 & 28 & 4,24 & $\begin{array}{c}\text { Acequia } \\
\text { Puertas de Murcia } \\
\text { (Orihuela) }\end{array}$ \\
\hline $\begin{array}{l}\text { Acequia } \\
\text { Puertas de Murcia }\end{array}$ & 6.321 & 28 & 14 & 2,21 & $\begin{array}{c}\text { Río Segura } \\
\text { (Ociopía, Orihuela) }\end{array}$ \\
\hline
\end{tabular}

Fuente: Información facilitada por Alejandro Aracil Orenes. Junta de Hacendados de la Huerta de Murcia.

*Nace en la Albatalía de la cola de dos brazales, el de Rosendo por el sur y otro sin nombre por el norte; el primero deriva de la Acequia de Bendamé, mientras que el segundo es ramal de la Acequia de Alfatego.

${ }^{* *} \mathrm{~A}$ los $2.592 \mathrm{~m}$ de su recorrido recibe el Azarbe de la Cruz que nace en la ciudad de Murcia a la altura de la Avenida Miguel de Cervantes con un recorrido de $916 \mathrm{~m}$.

TABLA 4. ENCABALGAMIENTOS EN EL ÁMBITO DE RIEGO DEL AZARBE MAYOR DEL NORTE, 2019

\begin{tabular}{lll}
\hline CAUCE & CRUCE & CAUCE \\
\hline Acequia Nueva del Raal & Superior & $\begin{array}{l}\text { Acequia de Cabecicos Land- } \\
\text { rona de los Condes }\end{array}$ \\
\hline Acequia Nueva del Raal & Superior & Merancho del Gilico \\
\hline Acequia Nueva del Raal & Superior & Landrona del Madrileño \\
\hline Acequia Nueva del Raal & Superior & Merancho del Meranchín \\
\hline Acequia Nueva del Raal & Superior & Landrona los Rosa \\
\hline Acequia Nueva del Raal & Superior & Landrona de los Cuenca \\
\hline Acequia Nueva del Raal & Superior & Landrona del Catalán \\
\hline Acequia Nueva del Raal & Superior & Landrona de los González \\
\hline Acequia Nueva del Raal & Superior & Landrona del Pozo \\
\hline Acequia Nueva del Raal & Superior & Landrona de los Alonsos \\
\hline Acequia Nueva del Raal & Superior & Landrona del Palmeral \\
\hline Acequia Nueva del Raal & Superior & Landrona de los Condes \\
\hline Acequia Nueva del Raal & Superior & Landrona de los Pina \\
\hline Acequia Nueva del Raal & Superior & Landrona de los Silvestres \\
\hline Acequia Nueva del Raal & Superior & Landrona de los Rosendos \\
\hline Acequia de Pitarque & Superior & Brazal Bajo de la Cueva \\
\hline Acequia de Pitarque & Superior & Merancho del Norte \\
\hline Merancho del Gilico & Superior & Merancho del Norte \\
\hline Merancho del Gilico & Superior & Landrona de Peñafiel \\
\hline
\end{tabular}

Fuente: Cartografía digital de la Comunidad de Regantes Junta de Hacendados de la Huerta de Murcia.
TABLA 5. ENCABALGAMIENTOS EN EL HEREDAMIENTO DE LA ACEQUIA DE LAS PUERTAS DE MURCIA

\begin{tabular}{lll}
\hline CAUCE & CRUCE & CAUCE \\
\hline Brazal de los Gerónimos & Superior & Azarbe del Riacho \\
\hline Brazal de los Gerónimos & Superior & Azarbe de la Gralla \\
\hline Brazal de los Gerónimos & Superior & Azarbe de En medio \\
\hline Brazal de los Clérigos & Superior & Azarbe de la Gralla \\
\hline Brazal de las Viñas & Superior & Azarbe de En medio \\
\hline Brazal de las Higueras & Superior & Azarbe de En medio \\
\hline Brazal de las Higueras & Superior & Azarbe de la Gralla \\
\hline Brazal de Salazar & Superior & Azarbe de En medio \\
\hline Brazal de Salazar & Superior & Azarbe de la Gralla \\
\hline Brazal de Salar & Superior & Azarbe de En medio \\
\hline Brazal de la Balsa & Superior & Azarbe de En medio \\
\hline Brazal de la Balsa & Superior & Azarbe de la Gralla \\
\hline Brazal de Seca & Superior & Azarbe del Camino \\
\hline Acequia de las Puertas de Murcia & Superior & Azarbe de la Gralla \\
\hline Brazal de Bonanza & Superior & Azarbe de Bonanza \\
\hline
\end{tabular}

Fuente: Elaboración a partir de la Cartografía Histórica (1943) del Juzgado Privativo de Aguas de Orihuela. 
azarbe utilizado para las canalizaciones que recogen las filtraciones procedentes de la Acequia de las Puertas de Murcia en la zona contigua de Orihuela. Con anterioridad, se puso de manifiesto que en la jerarquía de la retícula avenante, a los reseñados vocablos murcianos, se les atribuye la categoría de cauces menores, si bien no es de extrañar que este atributo cambie en la percepción popular debido a la considerable anchura que alcanzan desde su base, con 5 metros e incluso algo más, muestran en superficie una amplitud que puede oscilar, según tramos, de 12 a $15 \mathrm{~m}$ por la forma en talud de sus costados.

Esta retícula adquiere una mayor dimensión en el sector alicantino de la Huerta, ya que está presente en casi todas las demarcaciones de riego de sus heredamientos, desde el límite interprovincial hasta la numerosa red de evacuación que confluye en el río Segura a escasos metros de su desembocadura. En el laberinto de las canalizaciones de este trazado ingenieril, los diversos tipos de cruce son exponente de la maestría y conocimiento en el arte del uso y gestión de los recursos hídricos en esta región de escasa pluviometría y acusada aridez. Estas estructuras, bien sean subterráneas o aéreas, fueron posibles mediante la utilización de tubos metálicos o muros de sillería, unidos por lo general mediante mampostería ordinaria. Todo ello confiere al conjunto una extraordinaria solidez que contrasta con la existencia de unas zanjas excavadas en tierra sin enfoscar, bajo la amenaza continua de su desmoronamiento. La importancia de estas obras confiere envergadura y monumentalidad al gran edificio hidráulico que es la Huerta.

La superficie abastecida por el Azarbe Mayor del Norte con sus ramificaciones y prolongación cubre 1.410 ha, con repartos desiguales de tanda según cada arteria de riego, como se observa en la Tabla 6. Este acueducto desarrolló a lo largo de su recorrido un poblamiento lineal denominado Orilla del Azarbe que presenta un patrón característico del hábitat huertano, por cuanto se organiza siguiendo la dirección marcada por el eje de avenamiento. En sus brazas se emplazaron la red caminera y las viviendas, que en ocasiones ampliaron la superficie edificada al cubrir el propio cauce. A partir de 1977 se experimentó una importante modificación en su estructura, al concluir el proceso de canalización y en ocasiones de cimbrado. La finalidad era evitar riesgos en aquellos sectores que mantenían en sus inmediaciones mayor superficie urbanizada o mostraban un estrechamiento del vial por tratarse de una zona de tránsito muy concurrida al iniciarse en la primera corona periurbana
TABLA 6. SUPERFICIES DE RIEGO ABASTECIDAS POR EL AZARBE MAYOR DEL NORTE, 2019

\begin{tabular}{llll}
\hline CAUCE & RIEG0 (ha) & TANDA & DESAGÜE \\
\hline Acequia Raal Nuevo & 321,5368 & 14 días & Merancho del Gil \\
\hline Acequia de Pitarque & 156,2964 & 6 días & $\begin{array}{l}\text { Merancho de los } \\
\text { Pérez }^{23}\end{array}$ \\
\hline Azarbe Mayor del Norte & 307,8972 & 7 días & $\begin{array}{l}\text { Acequia Puertas de } \\
\text { Murcia }\end{array}$ \\
\hline Acequia Puertas de Murcia & 625,0875 & 7 días & Río Segura \\
\hline & $1.410,8179$ & - & Río Segura \\
\hline
\end{tabular}

Fuente: Datos facilitados por Patricio Ballester Carmona, Vicepresidente de la Junta de Hacendados de la Huerta de Murcia y por José Villalgordo Cerezo, Síndico de la Acequia de las Puertas de Murcia.

de Murcia. Unas actuaciones que se ejecutaron acorde a las necesidades que presentaba cada tramo, si bien todavía quedan partes sin recubrir, aunque minoritarias.

\section{Conclusiones y aportaciones}

La red de avenamiento es el factor clave en la configuración de la Huerta, pues su principal fin es erradicar el marjal para hacer factible la agrarización de este medio pantanoso. Una vez conseguido el objetivo, el acopio de aguas, se las vuelve a utilizar, asignando a estos cauces de drenaje la nueva función de regar y, por ende, contribuyeron a la expansión del regadío. La trascendencia de la red de avenamiento permanece vigente desde su implantación, pues no solo concentra la recogida de caudales tras los riegos, sino que además, recibe las aguas sobrantes procedentes de las colas de algunas acequias, sin olvidar la importante función receptora de las precipitaciones. Este último beneficio excede de lo propiamente agrícola e incide favorablemente en todas las poblaciones del entorno, hecho que conduce a reivindicar que su mantenimiento debería ser competencia del ámbito público y no solo representar una carga para los heredamientos regantes.

La importancia de los encabalgamientos en el diseño de la infraestructura hidráulica refleja un ámbito más tardío de colonización, pues predominan en aquellos terrenos más deprimidos de la llanura, con cota por debajo de la solera del Segura, lo que precisó una mayor agudeza en el arte de esta ingeniería, no exenta de dificultades como demuestra los dilatados períodos de tiempo hasta solventar los problemas indicados; resuelta finalmente, mediante la superposición de acue-

\footnotetext{
23. Confluye en el Merancho del Norte que al juntarse con el Merancho del Gi dan origen al Mancomunado que vierte aguas por Orihuela al río Segura.
} 
ductos para salvar esa enorme limitación, conseguir sanear los suelos encharcados y encontrar la solución satisfactoria, es el caso del analizado Azarbe Mayor del Norte, que concebido en el siglo XV, se consigue mejorar su construcción con la consiguiente expansión de las arterias de riego entre 1687-1701, para lograr su máxima eficiencia en la segunda mitad de la centuria pasada y erigirse como el modelo a extrapolar al resto del territorio huertano para su bonificación. Este subsistema de drenaje-riego es paradigma en la conexión de sendas Huertas, como exponente del manejo, uso y sostenibilidad del armazón hidráulico; unas acciones que implican, en cuanto al "manejo", la capacidad de gobernar o dirigir la búsqueda de acuerdos que beneficien a los implicados; el "uso", conlleva un saber hacer cotidiano aplicado por todo el colectivo y transmitido por la costumbre, fruto de la experiencia; por último, la "sostenibilidad", puesto que el aprovechamiento de los recursos hídricos alcanza su mayor expresión en la evolución dinámica del regadío, al utilizar para riego los drenajes por la retroalimentación que se da en sus canalizaciones. Conviene insistir en que no existe ni derroche, ni malgasto, ni despilfarro de agua en este circuito cerrado que reaprovecha continuamente los caudales disponibles.

El regadío tradicional de la vega del Segura debe reivindicar los atributos de eficiencia y viabilidad como valores inherentes al mismo, especialmente en aquellos métodos y técnicas agronómicas vernáculas, amenazadas por la supuesta modernización otorgada al riego por goteo, que se presenta como el prototipo de la competitividad y mejora en la gestión de los recursos hídricos. El proceso de gestación de la Huerta refleja la doble dinámica que ha atravesado este espacio, por un lado, "el grado de intensificación" logrado en el uso comunitario del agua, recurso limitado y escaso del que secularmente se ha sabido sacar el máximo partido con los caudales de retorno; por otro, "el grado de extensificación", por cuanto, el ejemplo seleccionado evidencia la importancia que tuvo para ampliar la superficie regada, con la erradicación del marjal insalubre, devenido a tierras fértiles. Sin olvidar que, ambos aspectos, contribuyeron al desarrollo territorial que buscó el equilibrio entre la manipulación inevitable de los recursos naturales y sus consecuencias medioambientales.

El paisaje identitario generado ha sido muy valorado por el Informe Dobris emitido por la Agencia Europea de Medio Ambiente (1998) al constituir un modelo cultural excepcional en su estructura y funcionamiento, que permanece vivo a pesar de las amenazas que se ciernen sobre él. Las medidas de desarrollo que preconiza la Política Agraria Comunitaria persiguen tres líneas estratégicas: la repercusión del cambio climático y la gestión sostenible de los recursos naturales; el mantenimiento de la superficie cultivada en toda la UE; y, por último, asegurar la producción viable de alimentos para abastecer zonas en las que se prevé un crecimiento poblacional. Estas pretensiones han estado siempre presentes en la esencia de la Huerta, pese a los agravios padecidos por las transformaciones que han experimentado los usos del suelo a favor de una ocupación residencial, industrial y de servicios.

El regadío resulta aquí, no obstante, una actividad eficaz y rentable, pues autores como Playán (1994) subrayan que se corresponde con un uso no consuntivo, en tanto que esos flujos, fruto de la percolación profunda producida por la técnica de riego a manta, han sido ya consumidos en terrenos anteriores. Por ello, el agua usada, especifica Aragüés (1994), se ve sujeta a un doble efecto, el "de concentración", derivado de la evapotranspiración de los cultivos, y el "de meteorización", provocado por la disolución de sales presentes en el suelo o en sustratos subyacentes. Ambos incrementan la salinización de estos caudales y producen la contaminación de las tierras receptoras, de ahí que la modernización, fundamentada casi exclusivamente en la implantación del goteo, no se encuentra respaldada mayoritariamente, si no viene avalada por una dotación de agua de calidad. Circunstancia agravada con el paso del tiempo porque el empleo de productos agroquímicos repercute negativamente, no sólo en la fauna y vegetación del Segura, sino al medioambiente en general.

Es preciso destacar los beneficios de diversa índole que aporta este sistema agrario, respondiendo a las dimensiones de la sustentabilidad, como son: económicos, espacio de producción y empleo que impulsa otras actividades asociadas; sociales, como la participación de todos los miembros de la familia en la actividad; ambientales, conserva biodiversidad, los cultivos fijan suelo, absorben aguaceros, son sumideros de $\mathrm{CO}_{2}$, expelen oxígeno, contribuyen a favorecer el ciclo del agua, evitan medios encharcados y las consecuencias nefastas para la salud, entre otros; y culturales se ha creado una idiosincrasia, un modo de vida pleno de aspectos tangibles e intangibles.

La crítica actual señala que el regadío tradicional derrocha agua y queda demostrado con el ejemplo presentado que reproduce un ciclo integral de la misma. Por otra parte, grupos ecologistas denuncian el recubrimiento con cemento de las cajas de los cauces, así como sus cimbrados, porque se pierde biodiversidad, sin em- 
bargo, solo en parte se puede considerar esta acusación, pues algunos permanecen excavados en tierra todavía y para el resto su fisonomía actual favorece la continuidad de diversos ecosistemas. El principal reto a abordar por este regadío tradicional para erigirse como una actividad económica competitiva, duradera, sostenible al fin, es exigir a los responsables de las políticas públicas sectoriales a las que compete la agricultura, una revisión y acuerdo sobre la verdadera eficiencia de lo que supone la modernización agraria. Esta pasa por la recuperación de los cultivos orgánicos y la accesibilidad a unos recursos hídricos de calidad, distribuidos en su justa medida, toda vez que, valorados como no consuntivos, puesto que la ingeniaría hidráulica concebida para la construcción de la Huerta permite una reutilización continua de las aguas, y, por tanto, obtener el mayor provecho y rentabilidad a los escasos volúmenes asignados por el órgano de gestión de la cuenca hidrográfica del Segura. En este sentido, sería deseable que la sociedad asimilara la Consideración 1 de la Directiva Marco del Agua (2000) en la que subraya que "el agua no es un bien comercial, sino un patrimonio que hay que proteger, defender y tratar como tal".

\section{BIBLIOGRAFÍA}

Agencia Europea de Medioambiente. 1998: Medio Ambiente en Europa: El Informe Dobris. Madrid, Oficina de Publicaciones Oficiales de las Comunidades Europeas, Ministerio de Medio Ambiente, Ministerio de Agricultura, Pesca y Alimentación.

Aragüés Lafarga, R. 1994: "Agricultura de regadío, calidad del agua y flujos de retorno", en: Symposium Nacional "Presente y Futuro de los Regadíos Españoles". Madrid, Ministerio de Fomento, Centro de Estudios y Experimentación de Obras Públicas,. 2, 69-86.

Azud de Alfeitamí. 1793: Real Provisión de Su Magestad y Señores del Consejo, por la qual se aprueban y mandan guardar las Ordenanzas formadas para el gobierno de la Aguas del Azud de Alfeitamí, término de la Villa de Almoradí, Reyno de Valencia. Almoradí, Imprenta Alonso, 1955.

Barranco Sánchez, M. y Herrero Carcelén, M. 1996: Historia de El Raal. Murcia, Ayuntamiento de Murcia, Junta Vecinal del Raal, Editorial KR.

Belmonte Rubio, J. 2015: San Pedro de La Ñora. Un Monasterio Jerónimo en la Huerta del Murcia, Murcia, edición del autor.

Calvo García-Tornel, F. 1982: Continuidad y cambio en la Huerta de Murcia. Murcia, Academia Alfonso X el Sabio
Canales Martínez, G. y De Juanes Rodriguez, F. 2014: "La construcción social de un paisaje en los Saladares de Albatera, siglos XVII-XX (Alicante)", en Rubio Medina, L. y Ponce Herrero, G. (Coords.): Imaginario, escenarios y gestión del patrimonio. México D.F., Servicio de Publicaciones de la Universidad Autónoma Metropolitana de Méjico, 170-184.

Canales Martínez, G. y Ponce Sánchez, M. ${ }^{a}$ D. 2019: Agua y Sostenibilidad. La monumentalidad del edificio hidráulico de la Huerta del Bajo Segura. Alicante, Cátedra Arzobispo Loazes, Universidad de Alicante y Diputación Provincial de Alicante.

Directiva 2000/60/CE Del Parlamento Europeo y Del Consejo: Por la que se establece un marco comunitario de actuación en el ámbito de la política de aguas. (DO, L 327 de 22 de diciembre de 2000).

Gea Calatayud, M. de 1995: "La construcción del paisaje agrario en el Bajo Segura. De los orígenes hasta la implantación de la red de riego-drenaje principal en el alfoz oriolano". Alquibla, Revista de Investigación del Bajo Segura. 1. Centro de Investigación del Bajo Segura Alquibla, 65-99.

Gil Olcina, A. 1988: "Precipitaciones y regímenes fluviales en la vertiente mediterránea española". Boletín de la Asociación de Geógrafos Españoles. 7, 1-12.

González Blanco, A. y García García, I. 1998: Repertorio alfabético de la toponimia de la Región de Murcia. Murcia, Editorial KR. Juzgado Privativo de Aguas de Orihuela, 2017: Ordenanzas del Juzgado Privativo de Aguas de Orihuela y Pueblos de su Marco. Orihuela, Gráficas Minerva, 19-75.

Junta de Hacendados de la Huerta de Murcia, 2008: Ordenanzas y Costumbres de la Huerta de Murcia 1849-2008. Murcia, Gráficas San Ginés.

Luzón, M. 1697: "Expediente de construcción de partidor de aguas por el Monasterio de San Pedro de La Ñora en el Azarbe Mayor de la huerta de Murcia, para la irrigación de sus tierras en los partidos o pagos de Monteagudo, La Urdienca, El Campillo y Santomera". Hacienda, sig. 3782. Archivo histórico provincial de Murcia.

Martínez Carrillo. M. ${ }^{a}$ LL. 1997: Los paisajes fluviales y sus hombres en la Baja Edad Media. El discurrir del Segura. Murcia, Servicio de Publicaciones, Universidad de Murcia.

Montenat, C. 1977: "Les bassins néogenes et quaternaires du Levant d' Alicante a Murcie (Cordilleres bétiques orientales, Espagne). Stratigraphie, paléontologie et évolution dynamique". Docum. Lab. Géol., 63. Universidad de Lyon, 1-345.

Playán Jubillar, E. 1994: "Eficiencia en el aprovechamiento del agua por el regadío", Geórgica, Revista del Espacio Rural. 3, 99-128.

Sánchez Baeza, E. 1983: La Ñora. Ayer y Hoy. Madrid, Gráficas Catena, S. L.

Torres Fontes, J. 1960: Repartimiento de Murcia. Murcia, Academia Alfonso X el Sabio. 
Torres Fontes, J. 1992-1993: "En la raya de los dos reinos. Beniel medieval". Anales de la Universidad de Alicante. Historia medieval, 9, 145-159. https://doi.org/10.14198/medieval.1992-1993.9
Vázquez Heredia, A. 2014: La desecación del almarjal y el nivel freático en la Huerta de Murcia. Murcia, Junta de Hacendados de la Huerta de Murcia. 